\section{International Scientific Journal Theoretical \& Applied Science}

p-ISSN: 2308-4944 (print) e-ISSN: 2409-0085 (online)

Year: 2015 Issue: $01 \quad$ Volume: 21

Published: $30.01 .2015 \quad$ http://www.T-Science.org
Elena Petrovna Zvyagintseva

Senior lecturer

of the Department "Foreign Languages - 2", Financial University under the Government of the Russian Federation (FinUniversity), Russia zV elena@list.ru

Section 21. Pedagogy. Psychology. Innovations in the field of education.

\title{
METAQUALITIES OF CONTEMPORARY UNIVERSITY STUDENTS THAT CAN INFLUENCE ACMEOLOGICAL PROCESSES IN THE CONTEXT OF FINANCIAL AND ECONOMIC PROFESSIONALISM
}

Abstract: The article determines the basic metaqualities of contemporary students that are connected with such acmeological processes as identifying determinants of a future specialist in the sphere of finance and economy as well as his/her adapting behaviour after graduating from university. The results of empiric research and survey at Financial University in Moscow are used as a scientific underground of the presented material.

Key words: metaqualities, acmeological processes, determinants, adapting behaviour, professionalism, university students.

Language: Russian

Citation: Zvyagintseva EP (2015) METAQUALITIES OF CONTEMPORARY UNIVERSITY STUDENTS THAT CAN INFLUENCE ACMEOLOGICAL PROCESSES IN THE CONTEXT OF FINANCIAL AND ECONOMIC PROFESSIONALISM. ISJ Theoretical \& Applied Science 01 (21): 28-31. doi: http://dx.doi.org/10.15863/TAS.2015.01.21.5

\section{МЕТАКАЧЕСТВА СТУДЕНТОВ ВУЗА, ВЛИЯЮЩИЕ НА АКМЕОЛОГИЧЕСКИЕ ПРОЦЕССЫ В РАМКАХ ФИНАНСОВО-ЭКОНОМИЧЕСКОЙ ПРОФЕССИОНАЛИЗАЦИИ}

Аннотация: В статье рассматриваются основные метакачества современных студентов, которые связаны с такими акмеологическими процессами, как определение детерминант будущего профессионала в финансово-экономической сфере, а также адаптивное поведение выпускников после окончания вуза. Результаты эмпирических исследований в Финансовом университете легли в основу данной статьи.

Ключевые слова: метакачества, акмеологические прочессы, детерминанты, адаптивное поведение, профессионализация, студенты вуза.

Многолетняя педагогическая практика автора, а также анализ психолого-педагогической литературы и современных научных исследований показывает, что проблема совершенствования процесса обучения и профессиональной подготовки специалистов остается по-прежнему актуальной, т.к. социальный заказ общества, поставленный перед вузами, на подготовку конкурентноспособного специалиста решен не в полной мере. Доказательством тому служат низкие темпы экономического роста и турбулентность Российской экономики, еe зависимость от углеводородов, высокий уровень инфляции и волатильность национальной валюты. Ведь кадры, как говорил один государственный деятель, решают все. Ведущие ученые и педагоги-практики обращались и продолжают обращаться как к анализу различных аспектов повышения качества обучения в целом, так и отдельных его элементов в частности. Многие из них считают, что совершенствование способов передачи знаний от наставников ученикам может привести к более высокому уровню эффективности обучения, воспитания, профессиональной подготовки будущих специалистов. В этой связи ученые разработали и продолжают развивать научные положения 
общей теории обучения и воспитания (Ю.К. Бабанский, В.П. Беспалько, М.Н. Скаткин [3]), дидактики высшей школы (С.И. Архангельский, П.Я. Гальперин, Ю.Ф Худолеев [1]), теории деятельности (Л.С. Выготский, И.А. Зимняя, А.Н. Леонтьев [7, с.64-97; 8, с.94-156]), научные положения психологической теории о профессионализме и компетентности (Е.В.Бондаревская, В.И.Загвязинский, Е.С. Полат $[9$, с.4-8]) и др.

Говоря о профессионализации образовательного процесса финансовоэкономической направленности, нужно отметить, что у разных специалистов этой сферы деятельности перечень характеристик и компетенций в период обучения будет варьироваться: финансовый аналитик, банкир, главный бухгалтер или аудитор обладают профессиональными знаниями, специфика которых разнится априори. Но обобщает процесс профессионализации образования, ориентированного на достижение акме, несколько конструктов. Основным из них является идея о том, что именно в студенческие годы человек строит фундамент здания своей профессиональной реализации в жизни. На этой базе потом можно воздвигать поэтапно все остальные компоненты профессионального становления и роста специалиста. От этой основы зависит то, станет ли выпускник вуза со временем мастером, или так и останется ремесленником (а иногда и подмастерьем). При всех различиях характеристик и компетенций, присущих представителям разных профессий финансово-экономической сферы, некоторые акмеологические процессы могут совпадать. Вопервых, это определение детерминант будущего профессионала в области финансов и экономики. Во-вторых, это адаптивное поведение выпускника в трудовом коллективе после окончания вуза. Практика показывает, что от уровня сформированности когнитивного, мотивационно-ценностного, конативного компонентов профессионально-ценностных ориентаций у будущих экономистов может зависеть и процесс адаптации выпускников вуза в трудовом коллективе на начальном этапе, и их успешность/ неуспешность в профессиональной деятельности в будущем. В-третьих, как показывают исследования в области педагогики и психологии, это единство множества аспектов, присущих социально-культурному развитию личности. Например, Е.В. Швачко и М.Е. Дуранов выделяют пять основных аспектов в этом ряду: философский, социальный, культурологический, социальнопсихологический, социально-педагогический [10, c.19-2].
Говоря о понятийном аппарате описываемого процесса, следует определиться с таким ключевым словом, как метакачества. Доктор психологических наук Э.Ф. Зеер определяет понятие метакачества как «способности, качества, свойства личности, обуславливающие, определяющие продуктивность широкого круга учебнопознавательной, социальной и профессиональной деятельности» [6]. Согласно исследованиям его научного коллектива, все метакачества можно в упрощенном виде разделить на две группы: широкого радиуса функционирования (познавательные, регуляторные, коммуникативные умения и навыки) и узкого радиуса функционирования (взаимоотношения человек-человек, человек-техника, человекприрода в процессе жизнедеятельности).

С целью определения метакачеств, которые будут востребованы в их будущей профессиональной деятельности, весной 2014 года было проведено анкетирование около 100 студентов третьего курса бакалавриата на двух факультетах Финансового университета: «Учет и аудит» и «Кредитно-экономический». На выбор респондентов повлияли следующие факторы:

1) студенты 3 курса уже точно определились с выбором профессии и специализации (разочарованные или сделавшие ошибку в выборе своей будущей профессии обучаемые отсеялись на 1-2 курсе);

2) эти студенты втянулись в учебный процесс (приняли условия обучения в Финуниверсите);

3) они имеют представление о том, что и как им предстоит делать на рабочем месте (общались с работодателями на Днях карьеры в вузе, а также со студентами, побывавшими на производственной практике);

4) учащиеся получили базовые знания в области выбранной специальности (посещали занятия преподавателей, представителей ведущих компаний, лекторов из зарубежных вузовпартнеров и т.д.).

Интересными оказались результаты данного исследования, а именно: самыми востребованными метакачествами, полагают студенты, будут их коммуникативные навыки (около 20\%), творческая самореализация, т.е. способность к самообучению, саморазвитию, самосовершенствованию и т.д. (18\%), профессиональная компетентность и ответственность (по 17\%), целеустремленность и аналитические способности (около $11 \%$ соответственно), знание иностранного языка (около 6\%). Данные метакачества во многом пересекаются с теми аксиологическими детерминантами, которые исследователи считают актуальными в процессе профессионального 
становления личности. Так, например, наиболее значимые аксиологические детерминанты данного процесса включают в себя, по мнению исследователя С.Н. Бегидовой, ориентацию личности на творческое саморазвитие; профессиональную компетентность, ментальность, честолюбие; гуманизм, положительную установку на профессиональную деятельность, акмеологическую культуру [2, с.2027]. Исследование показало, что следующие метакачества студентов вполне можно считать аксиологическими детерминантами:

1) положительная установка на профессиональную деятельность (умение вступать в коммуникацию в процессе социальной и профессиональной деятельности);

2) творческое саморазвитие (самоактуализация);

3) ориентация на профессиональную компетентность и ментальность (профессиональные знания и навыки, аналитические способности);

4) установка на акмеологическую культуру (например, знание иностранного языка, который расширяет личностные горизонты и обогащает субъект образовательного процесса культурным достоянием других народов).

Говоря о еще одном акмеологическом процессе - адаптивном поведении выпускника в трудовом коллективе после окончания вуза нельзя не упомянуть функции адаптивного поведения, которые описал в акмеологии ученый А.А. Деркач [4, с.11-25]. К данным функциям относятся профессионализация, социализация, интеграция, развитие и функция нормативного регулирования.

Интегративные процессы в настоящее время приобретают все большее значение. Интеграция (т.е. объединение ранее разрозненных частей в одно целое или желание стать частью целого) может быть горизонтальной и вертикальной. В студенческой среде она может проявляться как на локальном уровне (в процессе вливания в коллектив группы, курса, факультета и т.д.), так и на международном уровне (в тех случаях, когда вуз предоставляет студентам возможность стажироваться в вузах-партнерах, участвовать в программе двойных дипломов и т.д. [5, с.74-77]. После окончания вуза интеграция находит отражение в возможности влиться в трудовой коллектив, в сферу профессиональной и социальной деятельности и т.д. Общение с выпускниками экономического вуза после первого, самого решающего, года работы в коллективе показывает, что их адаптация на рабочем месте проходила успешнее и с меньшим стрессом, если в студенческие годы учащиеся добивались определенных успехов в сфере коммуникативной деятельности, вырабатывая в себе навыки общения в критических ситуациях или имитирующих поведение во время участия в переговорах, в процессе работы над кейс-стади. В экономической деятельности принятие ценностей трудового коллектива, его традиций, а также готовность обогащаться новыми знаниями с помощью коллег быстрее происходит во время тимбилдинга (в тех компаниях, где он имеет место быть). Нормативная функция адаптивного поведения поддерживается через передачу и сохранение профессиональной информации, тех ноу-хау, которые были созданы предыдущими поколениями специалистов, а также через способность следить за постоянными изменениями в сфере финансовой отчетности, современных экономических трендов и умение быстро обрабатывать эти пласты информации с помощью системного подхода.

Проведя краткий анализ отдельных компонентов акмеологических процессов, присущих развитию профессионально значимых качеств будущих экономистов, следует предложить некоторые рекомендации в рамках профессионализации высшего образования. Профессорско-преподавательскому составу и администрации вуза целесообразно было бы наряду с обучением студентов работать над актуализацией акмеологических факторов развития профессионализма личности будущего экономиста. Это могут быть: мотивация студента к самоизменениям и индивидуально-творческая самореализация через построение индивидуального вектора профессиональноличностного развития; онтогенез профессионального самосознания и способностей через организацию общения с лучшими представителями в сфере выбранной профессии; формирование у студентов общечеловеческих ценностей через проведение внеаудиторных мероприятий и проектов воспитательного характера в вузе; развитие рефлексии и саморегуляции в процессе учебы и во время производственной практики через создание в вузе департамента психологической поддержки студентов; использование индивидуальных потенциальных возможностей в соответствии с требованиями будущей профессиональной деятельности и условиями образовательной среды вуза через создание службы профессиональных коучеров. Самим обучаемым можно порекомендовать более активно использовать информационный, организационнометодический, социально-психологический потенциал вуза для развития не только профессионально значимых качеств, но и для самоактуализации и достижения акмеологических вершин; совершенствовать навыки самообучения в процессе профессиональной подготовки во время обучения 
в вузе. Девизом этого периода жизни обучаемых может стать изречение Эммануэля Мунье: «Личность - единственная реальность, которую мы познаем и которую одновременно возделываем изнутри».

\section{References:}

1. Arkhangelsky SI (1980) Uchebny protses V vyshey shkole: ego zakonomernye osnovy i metody. - Moscow: Vyshaya shkola.

2. Begidova SN (2012) Akmeologicheskie determinanty professionalnogo stanovleniya lichnosty. Vestnik Adygeiskogo gos. universiteta. V.1.

3. Bespal'ko VP (1989) Slagaemye pedagogitcheskoi tehnologii. - Moscow: Pedagogika.

4. Derkach AA (2013) V pomosh' issledovateljuakmeology. Akmeoligiya. №4.

5. Zvyagintseva EP, Zvyagintseva EA (2013) Integratsiya $\mathrm{v}$ inoyazychnoe obrazovatelnoe prostranstvo cherez prizmu polikulturnosty. Almanakh sovremennoy nauki i obrazovaniya. №4 (71).
6. Zeyer EF (2005) $\begin{array}{r}\text { Modernizatsiya } \\ \text { professionalnogo }\end{array}$ kompetentnostny podkhod. Moscow: MPSI.

7. Zimnyaya IA (1993) Sposob formirovaniya i formulirovaniya mysli kak realnost yazykovogo soznaniya. Moscow: Institut Yazykoznaniya RAN.

8. Leont'ev AN (1983) Deyatelnost. Soznanie. Lichnost. - Moscow: Pedagogika.

9. Polat ES (2001) Raznourovnevoe obuchenie. Inostrannye yazyki v shkole. №1.

10. Shvatchko EV, Duranov ME (2014) Aspektny podhod k sotsiokulturnomy razvitiyu litchnosty. Sovremennaya vyshaya shkola: innovatsionny aspect. №2. 